\title{
SISTEMAS AUTOMATIZADOS: DISCUSSÕES ACERCA DE SEUS BENEFÍCIOS PARA AS UNIDADES DE INFORMAÇÃO
}

\author{
J. A. MELO NETO' e C. M. O. MELO \\ ${ }^{1}$ Instituto Federal de Educação, Ciência e Tecnologia do Rio Grande do Norte (IFRN) \\ ${ }^{2}$ Universidade Federal do Rio Grande do Norte (UFRN) \\ joel.melo@ifrn.edu.br ${ }^{1}$ - cirlenemelo@bczm.ufrn.br ${ }^{2}$
}

Artigo submetido em maio/2013 e aceito em março/2014

\section{RESUMO}

Este artigo trata da importância da implantação de um sistema de automação em bibliotecas. Mostra a praticidade e segurança encontrada pelo profissional da informação em trabalhar com a catalogação automatizada em contraste com a catalogação manual. Este artigo também expõe a necessidade dos softwares serem compatíveis com os padrões e protocolos da catalogação cooperativa internacional. Além disso, demonstra a facilidade e o tempo economizados pelo catalogador quando o mesmo utiliza a cooperação de dados através de instituições que os disponibilizam na rede ou bibliotecas que permitem a importação de seus dados. Apresenta também as facilidades encontradas pelos usuários na busca e recuperação da informação por meio dos catálogos on-line. Discorre sobre os principais serviços remotos oferecidos aos clientes das instituições através dos catálogos. Por fim, disserta sobre a variedade de acervos virtuais que permitem o acesso de diversos tipos de documentos pelos usuários das bibliotecas.

PALAVRAS-CHAVE: Automação de Bibliotecas, Catalogação Cooperativa, Catálogos On-Line.

\section{AUTOMATED SYSTEMS: DISCUSSIONS ABOUT BENEFITS FOR UNITS OF INFORMATION}

\begin{abstract}
This article aims to analyze the importance of the implantation of an automation system in libraries. It shows the practicality and safety encountered by the information professional when working with automated cataloging in contrast with the manual cataloging. This article also exposes that the software must be compatible with the standards and protocols of international cooperative cataloging. Besides that, it demonstrates the ease and the time saved by the cataloguer when he uses the data cooperation through
\end{abstract}

institutions that provide it in the web or libraries that allow you to import their data. It also presents the conveniences encountered by the users in the search and retrieval of information through online catalogs. It discusses the main remote services offered to customers of the institutions through catalogs. Finally, it dissertates about the variety of virtual collections that provide access to various types of documents to the users of libraries.

KEYWORDS: Libraries Automation, Cooperative Cataloging, Online Catalogs. 


\section{INTRODUÇÃO}

A principal função de qualquer biblioteca é a disseminação da informação. Porém, para que essa informação chegue ao usuário, ela precisa ser trabalhada para que, então, possa ser disponibilizada de forma sistemática, facilitando, assim, a sua recuperação.

Seria muito inconveniente e até impossível se o usuário chegasse à unidade de informação e folheasse todo o acervo de livros, ouvisse todos os CDs ou assistisse a todos os DVDs até encontrar a informação desejada. Uma das principais funções do bibliotecário é tratar tecnicamente esses itens, de forma a simplificar a busca pelo usuário. O setor de processamento técnico de uma biblioteca é responsável pelo tratamento dado aos suportes informacionais, para que eles cheguem até o usuário de forma sistemática, prática e acessível.

Para Maciel e Mendonça (2000), o processamento técnico tem a mais importante função dentro de uma unidade informacional, pois do seu bom desempenho, vai depender a boa recuperação das informações e das próprias fontes. É onde se indica ou até aumenta a busca do leitor, usa-se terminologia adequada e cruzamentos oportunos. Através dele, é onde se estabelecem os catálogos, bases e demais recursos que consentem no rastreamento das informações e dos itens. Onde se fornece o verdadeiro suporte para a realização das pesquisas documentais, a base da investigação científica.

Mey e Silveira (2009, p. 7) definem catalogação como,

O estudo, preparação e organização de mensagens, com base em registros de conhecimento, reais ou ciberespaciais, existentes ou passíveis de inclusão em um ou vários acervos, de forma a permitir interseção entre as mensagens contidas nestes registros do conhecimento e as mensagens internas dos usuários.

O resultado do trabalho do catalogador pode ser visto através do catálogo, que consiste no principal instrumento de representação de documentos em bibliotecas.

Catálogo é um meio de comunicação, que veicula mensagens sobre os registros do conhecimento, de um ou vários acervos, reais ou ciberespaciais, apresentando-as com sintaxe e semântica próprias e reunindo os registros do conhecimento por semelhanças, para os usuários desses acervos (MEY; SILVEIRA, 2009, p. 12).

Antigamente, havia somente catálogos manuais em formato de livros, folhas soltas, listas impressas ou mais comumente, em fichas. Para localizar a informação desejada era necessário o usuário consultar fichários enormes, buscando remissivas em ordem alfabética por título, autor, assunto, série, em uma quantidade interminável. E muitas vezes, outros usuários retiravam estas fichas do local correto ou até mesmo desaparecia com algumas delas, prejudicando a recuperação da informação.

Dessa forma, a busca nos catálogos tornou-se morosa e os obstáculos enfrentados pelos usuários, o público-alvo, eram infinitos. Além disso, por não fazer uso, ainda, das tecnologias, os usuários enfrentavam dificuldades no atendimento e na busca pela informação, o que gerava certa rejeição na utilização da biblioteca. 
A partir da década de 60, houve o desenvolvimento dos recursos computacionais, a tecnologia ia avançando e fazia-se necessário, acompanhá-la e usufruir de seus benefícios.

Até que ponto a automação das bibliotecas facilitaria todo esse processo? Será que isso realmente iria ajudar o usuário na busca e aquisição do produto informacional? Haveria mais qualidade na oferta dos produtos e serviços? Isto, realmente, iria facilitar o trabalho do bibliotecário?

Nos dias atuais, mais do que nunca, a informática domina todas as áreas do conhecimento humano. $E$ as bibliotecas não poderiam ficar alheias a essa nova tendência. Assim como em todos os setores da sociedade, elas também foram se automatizando e oferecendo, desta forma, cada vez mais produtos e serviços, facilitando o trabalho dos bibliotecários catalogadores, como também, auxiliando o usuário na recuperação da informação.

"A atuação eficaz do profissional da informação depende, e muito, de ferramentas tecnológicas que possibilitem o desenvolvimento das diversas atividades informacionais" (CÔRTE et al., 2002, p. 11).

Hoje, não é necessário consultar várias fichas a procura do documento pretendido. Com alguns cliques é possível selecionar o autor, título, assunto ou outros campos e receber como resposta do sistema um rol de opções de obras, periódicos, multimeios e até documentos virtuais. E ainda há a possibilidade do usuário fazer essa pesquisa em casa, no trabalho ou na própria biblioteca. Onde estiver, o usuário pode realizar suas buscas com facilidade e rapidez através dos sistemas automatizados.

Especificamente no caso do processo de informatização, os avanços tecnológicos associados às exigências atuais dos usuários direcionam para a seleção e aquisição de software e hardware com características funcionalmente mais diversificadas, privilegiando a interligação das funções de uma biblioteca, numa linguagem que permita a integração usuário/máquina (CÔRTE et al., 1999, p. 241).

As bibliotecas estão se modernizando e a automação auxilia neste sentido, pois todos os processos informacionais dentro de uma unidade da informação dependem da informática. Desde a entrada de dados, passando pela recuperação da informação até o empréstimo automatizado, é de extrema relevância a utilização de máquinas computacionais.

A modernização das bibliotecas está diretamente ligada à automação de rotinas e serviços, com o intuito de implantar uma infra-estrutura de comunicação para agilizar e ampliar o acesso à informação pelo usuário, tornando-se necessário haver uma ampla visão da tecnologia da informação e sua aplicação nas organizações (CÔRTE et al., 1999, p. 242).

O maior benefício com a automação das bibliotecas é a otimização das atividades, não só em relação aos usuários, como também ao controle e formação do acervo, catalogação, levantamentos bibliográficos, serviços de empréstimo, renovação, devolução, reserva de obras, processamento técnico etc. (FIGUEIREDO, 1998 apud CÔRTE et al., 1999.).

Os sistemas de gerenciamento de bibliotecas acham-se hoje consolidados como ferramenta essencial no suporte a serviços eficazes para os clientes, gestão de 
acervos e, em geral, administração dos serviços prestados por bibliotecas e outras instituições que provêem acesso a coleções de documentos. $O$ foco desses sistemas está na manutenção, desenvolvimento e controle do acervo. Suportam seleção, encomenda, aquisição, confecção de etiquetas, catalogação e controle de circulação do acervo da biblioteca (ROWLEY, 2002, p. 315).

Outra importante função desses sistemas é que eles permitem descobrir a demanda de empréstimos ou solicitações de determinados títulos. Através de relatórios estatísticos, consegue-se visualizar quais livros são mais ou menos emprestados e reservados. $E$, através destas informações, em outro momento, a biblioteca pode avaliar se deve adquirir, ou não, mais exemplares de determinado título ou até mesmo desbastar outros, auxiliando em outra importante área do gerenciamento da biblioteca que é a formação e desenvolvimento de coleções.

A fim de se conseguir uma busca com qualidade, é de extrema importância o catalogador ser eficaz em todas as etapas. É necessário haver qualidade na indexação, utilizar os padrões, extrair palavras-chave compatíveis com os assuntos abordados na obra, dentre outros. Muitas vezes, o usuário final não recupera a informação desejada, não por falta de argumentos plausíveis, mas por falta de qualidade no processo da catalogação.

A questão crucial é que o processo de recuperação depende muito das etapas de indexação e armazenamento, as quais determinam, em grande medida, a estratégia melhor possível para as buscas feitas num sistema de recuperação da informação (ROWLEY, 2002, p. 162).

Como os sistemas automatizados permitem ao bibliotecário trabalhar com mais rapidez, é possível para o profissional atuar em outras áreas da unidade da informação, como utilização de estratégias de marketing, interação mais próxima com os usuários e até mesmo investir na sua própria capacitação profissional.

Rech (1985 apud LOURENÇO,1998, p. v) afirma que

[...] o uso do computador libera o bibliotecário para as funções que realiza junto ao usuário melhorando assim a relação entre o bibliotecário e seu usuário, possibilitando um maior aproveitamento deste profissional quanto ao seu potencial como pesquisador.

Um fator importante para ser levado em consideração a respeito dos sistemas de automação é escolha correta de um bom software, que atenda as necessidades da unidade de informação. Lourenço (1998) acredita que é necessário ser realizado um estudo sério em relação à escolha dos programas oferecidos as bibliotecas, visto que, são eles que promovem o sucesso ou o fracasso de um projeto de automação, podendo ocasionar até mesmo um retorno negativo em termos de custo-benefício para as mesmas. Com isso, deve-se analisar se esse sistema é compatível com todos os padrões e normas da catalogação cooperativa mundial.

Atualmente, existem excelentes softwares nacionais e internacionais, bastante acessíveis, para todos os tipos de bibliotecas, inclusive gratuitos, com todos os requisitos necessários para a padronização da catalogação em rede, item essencial nos dias de hoje. 
Este artigo teve como base uma revisão teórica, utilizou-se como metodologia a pesquisa bibliográfica em livros, artigos científicos, trabalhos acadêmicos, trabalhos apresentados em eventos e documentos eletrônicos. Seu objetivo é elencar os benefícios dos sistemas automatizados desde que sejam compatíveis com todos os padrões, formatos e normas exigíveis na catalogação internacional.

\section{CATALOGAÇÃO AUTOMATIZADA}

A tecnologia da informação, com toda a sua interdisciplinaridade, tem atingido, sem exceção, todas as áreas do conhecimento humano. Na Ciência da Informação não poderia ser diferente. A informática provocou e tem provocado grandes mudanças na organização e funcionamento das bibliotecas. A informatização foi o resultado de uma reflexão relacionada às velhas estruturas com o objetivo de formar uma nova organização. Os antigos esquemas de tratamento dos itens foram revistos com a finalidade de conceber um processamento integrado e eficiente (CAFÉ; SANTOS; MACEDO, 2001).

O profissional da informação percebe a facilidade em trabalhar com a catalogação automatizada nas bibliotecas, pois há uma infinidade de recursos disponíveis, com o intuito de ajudá-lo nas suas atividades cotidianas de tratar e disponibilizar a informação trabalhada para o usuário.

Antes da automação das bibliotecas, o bibliotecário catalogador encontrava diversas dificuldades para executar o seu trabalho. Ele tinha que utilizar grandes fichários para arquivar cartões em papel e neles catalogar entradas relacionadas a assuntos, autores, títulos das obras, demandando mais tempo na realização dessas atividades.

Com os sistemas automatizados, tudo foi facilitado. Agora, o profissional bibliotecário tem apenas que digitar no computador alguns dados referentes aos itens e, automaticamente, esses dados estarão disponíveis para o usuário através do catálogo.

Caso o software esteja compatível com os padrões de catalogação cooperativa, este serviço fica ainda mais fácil e rápido, pois o bibliotecário não terá que catalogar novamente o item já catalogado por outro profissional, basta importá-lo e alterar as informações necessárias no sistema.

\footnotetext{
A adoção de normas e padrões internacionais, no tratamento da informação e no intercâmbio de dados bibliográficos, constituem a principal base para a atualização e a agilidade dos serviços bibliotecários em todo o mundo, com o objetivo de concretizar a interconectividade das instituições, ampliar a abrangência de acesso à informação e otimizar o atendimento das demandas dos usuários (KRZYZANOWSKI et al., 1997, p. 175).
}

Caso a biblioteca disponibilize um catálogo manual em fichas e vise migrar estes dados para a catalogação automatizada, há esta possibilidade através da conversão retrospectiva, que, segundo Santos e Ribeiro (2003 apud SANTOS; GALO, 2012) "é a conversão de registros de um catálogo manual (em fichas) para o formato legível por máquina (computador)". Porém, ao realizar esta conversão, deve-se atentar para o processo da representação descritiva, pois é ela que deve determinar a qualidade da base. Se a catalogação não estiver da forma correta, o 
sistema não permitirá a leitura dos dados de forma eficaz, completa e precisa (SANTOS; GALO, 2012).

Para que esta conversão seja eficiente, deve-se considerar que o sistema de automação esteja compatível com os padrões da Biblioteconomia, principalmente o AACR2 e o formato MARC21. A catalogação retrospectiva diferencia-se da catalogação usual, principalmente por trabalhar com informações pré-existentes, onde as mesmas deverão ser aperfeiçoadas, para então ser disponibilizadas.

Reggini (1998 apud GUSMÃO, 2001, p. 39) relata três fases de incorporação das novas tecnologias de informação no processo de automação de bibliotecas.

1a fase - Automação independente, onde os módulos de um programa não se comunicam entre si, são sistemas produzidos localmente ou vendidos por empresas comerciais.

2a fase - Automação integrada, nesta, os módulos de um sistema comunicam-se entre si, normalmente em rede local, com funções administrativas e tecnológicas das bibliotecas. Também são sistemas vendidos por empresas ou desenvolvidos localmente.

3a fase - Conexão entre instituições em rede, que se compartilham remotamente, com seus processos, serviços e recursos.

Estas fases podem ocorrer aleatoriamente ou não, dependendo do processo de automação de cada biblioteca.

Há dez anos, talvez as duas primeiras fases fossem importantes para as bibliotecas no processo de informatização, porém, hoje, elas representam um retrocesso nas mesmas, pois não importa somente ter uma unidade de informação automatizada, mas também que ela esteja conectada em rede, com outras instituições compartilhando seus produtos e serviços de forma padronizada.

As bibliotecas são instituições que têm necessidade de cooperar entre si e trabalhar integradamente em diversas atividades. Quanto maior a integração, maiores tornam-se os acervos, mais rapidamente produz-se a representação bibliográfica e menores são os custos. Hoje, com todas as tecnologias disponíveis, é impossível pensar em bibliotecas não integradas a rede (MEY; SILVEIRA, 2009).

\subsection{CATALOGAÇÃO COOPERATIVA}

Pode-se conceituar catalogação cooperativa como uma atividade do processamento técnico de uma unidade de informação, onde diferentes bibliotecas, interligadas em uma mesma rede, com os mesmos padrões e normas, compartilham suas informações bibliográficas, possibilitando a troca de dados entre elas, poupando tempo e serviço, objetivando a recuperação mais eficiente da informação.

A catalogação cooperativa se dá quando um grupo de bibliotecas se une procurando eliminar a duplicação de esforços e o desperdício de recursos [...]. 0 avanço da tecnologia da informação possibilitou o compartilhamento de informações catalográficas de modo instantâneo. A catalogação cooperativa pode ser colocada em prática entre bibliotecas que estão em países ou continentes distintos (LOPES, 2010, p. 43-44). 
Para que a catalogação cooperativa seja uma realidade, é preciso que as bibliotecas estejam interligadas de alguma forma. As bibliotecas em rede são um grupo de bibliotecas que compartilham dados e informações, possibilitando o desenvolvimento de serviços e programas. Sem as redes de bibliotecas, a catalogação cooperativa não existiria, visto que elas estão diretamente ligadas (SANTOS; SANTOS, 2007).

Antigamente, as bibliotecas tinham seus próprios padrões de catalogação, porém, com o surgimento do trabalho em rede, houve a necessidade de se criar normas e protocolos para que fosse possível o intercâmbio de registros bibliográficos. Devido a isso, foram desenvolvidos o AACR e o MARC e a biblioteca que não os utiliza está fadada ao isolamento (LOPES, 2010).

Podemos construir a biblioteca digital mais avançada do mundo, com as tecnologias mais sofisticadas, com os documentos mais atraentes, com 0 catálogo mais eficiente, mas, se não utilizarmos a Rede, estaremos nos privando do instrumento que torna uma biblioteca digital um sistema centrado no usuário (TAMMARO, SALARELLI, 2008, p. 85).

No Brasil, é possível cooperar com a Rede Bibliodata, com a Biblioteca Nacional e alguns sistemas automatizados criaram uma rede exclusiva de cooperação entre seus clientes como, por exemplo, o Pergamum. Dentre essas, a mais completa e conhecida é a Bibliodata.

\begin{abstract}
A Bibliodata é uma rede cooperativa de bibliotecas brasileiras, onde as bibliotecas participantes possuem seus acervos representados no catálogo coletivo Bibliodata. A rede proporciona a realização de catalogação cooperativa e o compartilhamento de produtos e serviços (LOPES, 2010, p. 49).
\end{abstract}

O autor afirma ainda, que a Rede Bibliodata foi fundada pela Fundação Getúlio Vargas (FGV), uma instituição privada, sem fins lucrativos, em 1944, com o objetivo de servir como um centro de documentação no país.

A partir de 1 o de janeiro de 2013, a Rede Bibliodata passou a ser coordenada pelo Instituto Brasileiro de Informação em Ciência e Tecnologia (IBICT). O acesso a essa rede dá-se através de login e senha do profissional da informação da biblioteca cooperante. A pesquisa segue os mesmos padrões de busca de um catálogo on-line (autor, título e assunto). O sistema lista os registros de todas as bibliotecas que possuem o item pesquisado. Com isso, o bibliotecário pode analisar e selecionar o registro mais adequado aos padrões da sua biblioteca.

Todos os registros são salvos em uma pasta do CatBib, este é um software utilizado para editar os registros importados e implantar documentos que não foram encontrados na Bibliodata. Após a catalogação dos itens no CatBib, deve-se exportar todos os títulos para o sistema da biblioteca.

Outro recurso disponível na Bibliodata é o compartilhamento da base de autoridades de autor, assunto, série e título. Os procedimentos são os mesmos da pesquisa por registros bibliográficos.

As bibliotecas que fazem parte dessa rede têm sido amplamente beneficiadas com as vantagens da catalogação cooperativa, fazendo com que seus acervos se desenvolvam com menos gastos e mais qualidade em seu processamento técnico (LOPES, 2010). 
Em um estudo realizado por Nascimento (2000), descobriu-se que o tempo realizado pelo catalogador com a cooperação na Rede Bibliodata é bem menor do que quando se implanta um novo item. Segundo dados da autora, a implantação de uma obra original, sem cooperação, leva em torno de 1 hora e 20 minutos para ser finalizada e com cooperação, cerca de 19 minutos em média. No final de um dia de trabalho, o que implantou originalmente, produziu cerca de 6 itens e o que cooperou gerou 25 documentos.

Além da cooperação, o profissional bibliotecário tem a possibilidade de importar os dados em MARC de catalogações de outras instituições como, por exemplo, a Library of Congress (LC), a Biblioteca Nacional de Portugal, a biblioteca da Universidade de Coimbra, a American University Library, a biblioteca da Universidade Santiago de Compostela, a Fundação Biblioteca Nacional (FBN) e todas as outras instituições que disponibilizam o formato MARC em seus catálogos online.

Constata-se que, sem as normas e padrões internacionalmente adotados, a catalogação automatizada torna-se impossível e a biblioteca fica isolada de outras instituições, além de dificultar as atividades do catalogador, fazendo com que ele deixe de utilizar todos os recursos da cooperação.

\subsection{NORMAS E PADRÕES DOS SISTEMAS DE AUTOMAÇÃO}

A prática da catalogação necessita de normas e padrões específicos para a padronização de seus itens nos sistemas de automação. É imprescindível a utilização de requisitos essenciais, destacando-se o AACR2, o código RDA, o formato MARC21 e o protocolo Z39.50.

\subsubsection{Código AACR2}

Em pleno século $X X$, ainda não havia um código de catalogação único. Cada país tinha o seu próprio código. No Brasil, a partir de 1940, adotou-se o Código da Vaticana, que foi um código criado por um bibliotecário norueguês. Porém, a Vaticana foi perdendo suas forças na medida em que iam surgindo diversos códigos de catalogação até a década de 60 (MEY; SILVEIRA, 2009).

Em 1967, foi publicada, em trabalho conjunto da American Library Association (ALA), Canadian Library Association e a Library Association (Inglaterra) a primeira edição das AngloAmerican Cataloguing Rules (AACR) que foi editado no Brasil em 1969, traduzido como Código de Catalogação Anglo-Americana, passando a ser adotado em quase todas as escolas de Biblioteconomia brasileiras. A partir daí, em 1978, surgiu a segunda edição, AACR2 e, em 1988, uma segunda edição revista, AACR2R, com várias emendas e revisões até 2005 (MEY; SILVEIRA, 2009).

A bibliotecária Antonia Motta de Castro Memória Ribeiro fez uma adaptação para o português do próprio AACR2, cujo título é "Catalogação de recursos bibliográficos: AACR2R em MARC21". Essa versão é muito utilizada pelos bibliotecários no Brasil. Embora não substitua as AACR2, acredita-se que é o código mais utilizado pelos bibliotecários no país (MEY; SILVEIRA, 2009). 


\title{
2.2.2 Código RDA
}

A partir de 2003, vêm ocorrendo seguidas reuniões com especialistas da International Federation of Library Associations and Institutions (IFLA) com o objetivo de se criar um novo código internacional de catalogação. Com isso, em 2004, foi constituído o Joint Steering Comittee for the Development of AACR (Comitê Gestor Conjunto para o Desenvolvimento das AACR), que previa o lançamento das AACR3. Porém, tornou-se o comitê para o novo código de descrição e acesso aos recursos, Resource Description and Access, conhecido como RDA (MEY; SILVEIRA, 2009).

O RDA foi criado para dar maior flexibilidade e extensibilidade necessária para acomodar novos recursos na representação descritiva e ser aplicado a qualquer ambiente informacional, seja ele digital ou convencional possibilitando as interações necessárias às buscas e explicitando de forma clara e objetiva, correspondendo também às necessidades dos usuários não presenciais (CORRÊA, 2008).

Diferente das AACR2, o RDA permite a catalogação em todos os tipos de materiais e ambientes informacionais, inclusive digitais. Por ser maleável, torna possível estender a catalogação descritiva a novos itens que eventualmente possam surgir.

\begin{abstract}
O RDA, que oferece uma estrutura sólida, integrada e flexível se propõe a buscar soluções para algumas dificuldades e tem a seu favor as tecnologias de informação e comunicação (TICs), que facilitam a solução de problemas de armazenamento, recuperação, acesso e transmissão de informação e intercâmbio de registros bibliográficos, minimizando as barreiras econômicas e as divergências de ideais em relação ao esquema de descrição adotado (CORRÊA, 2008, p. 54).
\end{abstract}

A Library of Congress iniciou os testes para implantação do RDA com a colaboração de 25 instituições parceiras nos Estados Unidos. Os testes tiveram início em um período de aprendizagem entre os meses de julho a setembro de 2010. De outubro a dezembro de 2010, houve um teste formal, onde as instituições criaram registros no RDA. A LC, finalmente, implantou o RDA em 31 de março de 2013.

\subsubsection{Formato MARC21}

Houve um tempo, em que os bibliotecários norte-americanos sentiram a necessidade de não catalogar novamente o que já tinha sido catalogado, ou seja, eles queriam trocar registros bibliográficos entre suas bibliotecas. Porém, os sistemas existentes não eram compatíveis. A solução encontrada por eles foi se juntar a Library of Congress (LC) para desenvolverem um formato de intercâmbio de registros, mesmo entre sistemas diferentes.

No início da década de 50, um grupo de bibliotecários formado pela própria LC realizaram estudos sobre a possibilidade de utilizar recursos computacionais para automatizar parte de seus serviços. Na medida em que os resultados iam tendo êxito, a direção da biblioteca convocou um grupo de trabalho composto por bibliotecários e analistas de sistemas para encontrar uma forma de converter os dados das fichas catalográficas a fim de gerar o repertório bibliográfico. Desta forma, em 1966, iniciou-se um projeto piloto idealizado pela LC que possibilitava fornecer as bibliotecas dados de catalogações legíveis por máquinas, surgindo assim o Machine-Readable for 
Cataloging (MARC) que significa registro catalográfico legível por computador (CÔRTE et al., 1999).

Em 1968, foi lançado o MARC II e no início da década de 70, ele foi ampliado para atender, além de livros, publicações seriadas, materiais cartográficos e manuscritos. Nesta mesma década, o nome mudou para USMARC. Outros países, inclusive o Brasil com o seu CALCO (Catalogação Legível por Computador), começaram a desenvolver seus modelos próprios, mas sempre adaptado ao modelo original da LC. Em 1976, o formato evolui para UNIMARC (Universal MARC) pretendendo-se padronizar internacionalmente. Porém, até hoje os padrões MARC de alguns países persistem. Na década de 90, houve grandes esforços em unificar um padrão único, assim surgiu o MARC21 (MORENO, 2006).

De acordo com Balby [200-], um formato de intercâmbio é uma representação padronizada do registro bibliográfico em meio legível por computador de forma que sistemas diferentes possam ler e processar os diversos elementos do registro sem a necessidade de conversão de dados.

O MARC é um formato de intercâmbio formado por um conjunto de códigos e designações de conteúdos definido para codificar registros que são interpretados por máquina. Seu objetivo principal é possibilitar o intercâmbio de dados, ou seja, importar dados de diferentes instituições ou exportar dados de sua instituição para outros sistemas ou redes de bibliotecas através de programas de computador desenvolvidos especificamente para isto (PONTIFÍCIA UNIVERSIDADE CATÓLICA DO RIO DE JANEIRO, 2010).

O padrão MARC permite o compartilhamento entre bibliotecas dos seus recursos bibliográficos promovendo a comunicação entre diferentes sistemas e permitindo que elas substituam seus sistemas de automação, porém sem perda da compatibilização dos dados (LOPES, 2010).

O MARC utiliza números, letras e símbolos gráficos que são subdivididos em campos fixos e variáveis, subcampos e indicadores, utilizados para representar um item em um sistema de automação. Ele individualiza o documento, tornando-o único em toda biblioteca ou até mesmo em uma rede de bibliotecas interligadas.

Enquanto a catalogação do documento utiliza as regras AACR2 para definir quais são e a forma das entradas e descrever fisicamente, o documento e as tabelas de classificação auxiliam na definição de seus assuntos, o formato MARC organiza essas informações de forma a serem lidas pelo computador e possibilita a descrição bibliográfica de diferentes tipos de documentos (monografia, arquivo de computador, música, material cartográfico e outros) (OLIVEIRA et al., 2004, p 180-181).

Em âmbito geral, o padrão MARC possibilita adicionar informações, definir campos para uso local, atualizar informações existentes, atribuir pontos de acesso recuperáveis e possibilita a catalogação cooperativa, flexibilizando o processo de catalogação, através da interoperabilidade que é o processo de assegurar que sistemas, procedimentos e a cultura de uma organização sejam gerenciados de modo a maximizar as oportunidades para intercâmbio e reuso de informações (DZIEKANIAK et al., 2008). 
O principal formato de intercâmbio de dados em sistemas de automação no mundo é o MARC. Devido a isso, torna-se imprescindível em um software de bibliotecas a utilização deste formato, para que a unidade de informação possa compartilhar seus registros, poupando o tempo do bibliotecário, disponibilizando com mais agilidade o item para os usuários, tendo sempre a ideia de não catalogar novamente algo que já foi catalogado, uniformizando e padronizando a informação na rede.

\subsubsection{Protocolo Z39.50}

A LC em conjunto com o Online Computer Library Center (OCLC) e a Research Libraries Information Network (RLIN), desenvolveram um protocolo com o intuito de ajudar na recuperação e transferência de dados em formato bibliográfico entre processadores ligados em rede, cujo número de série é Z39.50. A atual versão do protocolo data de 1995 com atualização em 2003 e foi registrada como "Information Retrieval (Z39.50); Application Service Definition and Protocol Specification, ANSI/ISO Z39.50-2003" (TAMMARO, SALARELLI, 2008).

Para Moen (1995, apud ROSETTO, 1997, p. 2)

Z39.50 é um protocolo de comunicação entre computadores desenhado para permitir pesquisa e recuperação de informação - documentos com textos completos, dados bibliográficos, imagens, multimeios - em redes de computadores distribuídos. Baseado em arquitetura cliente/servidor e operando sobre a rede Internet, o protocolo permite um número crescente de aplicações. E como esse ambiente é muito dinâmico, no qual o protocolo é aplicado, é preciso que a norma seja constantemente analisada e atualizada para proporcionar as mudanças de que os criadores, provedores e usuários de informação necessitam.

O Z39.50 tem como objetivo principal disponibilizar a recuperação da informação na Web em computadores distintos, de forma padronizada, a partir de uma única interface de busca, até mesmo em diferentes sistemas e servidores, desde que os mesmos possuam programas e interfaces compatíveis com o protocolo.

\section{ACESSO A INFORMAÇÃO NOS CATÁLOGOS ON-LINE}

A biblioteca tem como objetivo principal oferecer conteúdo informacional a toda sua comunidade, sendo um espaço de múltipla comunicação, que visa facilitar a aprendizagem, disponibilizando itens informacionais de maneira ágil de modo a possibilitar a geração de novos conhecimentos (OLIVEIRA, 2008).

A multiplicidade de funções produzidas pelo surgimento das novas tecnologias facilitou a busca de informação. Hoje, tem-se a possibilidade de utilizar variados recursos, impensáveis algumas décadas atrás e até expandir os produtos oferecidos com a finalidade de obter a satisfação total do usuário.

Os bens e serviços oferecidos aos usuários devem ser integrados proporcionando a flexibilização necessária para a oferta de serviços de qualidade, que agreguem valor, adaptados à diversidade de usuários e diferentes locais para viabilizar o produto, com foco no cliente, já que cada 
pessoa ou grupo tem uma diferente necessidade de informação (GARCEZ; RADOS, 2002, p. 46).

É possível pesquisar itens em catálogos informatizados de bibliotecas nos diversos campos, acessar o histórico pessoal de livros emprestados, devolvidos e renovados, verificar suspensões dos serviços da biblioteca, reservar e renovar obras etc.

Algumas bibliotecas oferecem também através de seus catálogos, alguns serviços em rede que possibilitam o acesso a diversos materiais como documentos em texto completo, artigos, vídeos, fotos, imagens históricas, sons, mapas, partituras, dentre outros.

Salienta-se a importância dos programas de bibliotecas estarem vinculados ao sistema acadêmico da instituição, para que os dados pessoais dos usuários possam ser migrados, otimizando o tempo dos operadores que trabalham nas seções de atendimento das unidades de informação. Além de fornecer mais segurança, uma vez que a instituição terá como visualizar as pendências de cada usuário e ter acesso ao documento de nada consta ou declaração de quitação, coibindo a não devolução das obras.

Todos esses serviços são disponibilizados com agilidade e flexibilidade, em rede, à distância, ou seja, sem a necessidade do usuário estar fisicamente na biblioteca ou setor acadêmico de sua instituição.

Com a introdução das tecnologias da informação, o acesso dos usuários ao conteúdo do acervo das unidades de informação tornou-se mais ágil e dinâmico, não sendo necessário ao usuário se locomover até uma biblioteca para realizar pesquisas bibliográficas, para renovar um material ou solicitar a reserva de um item específico (OLIVEIRA, 2008, p. 74).

Atualmente, os catálogos apresentam-se em fichas, na forma impressa, em CD-ROMs, e principalmente em sistemas automatizados com acesso via web (CUNHA, 2001 apud KAFURE, 2004).

Com a popularização da informática e da Internet, observa-se a considerável substituição dos catálogos manuais pelo automatizados nas unidades de informação. A facilidade e praticidade na utilização dos mesmos tornam seu uso atrativo até mesmo para quem não tem amplo domínio das tecnologias da informação.

Para Oliveira (2008, p. 74-75),

Os catálogos automatizados tornam possível a utilização de vários dos recursos (catálogos por autor, título e assunto; de periódicos, de matérias especiais, índices, entre outros) por muitos usuários ao mesmo tempo. A busca de informação no ambiente do catálogo on-line torna-se dinâmica e rápida e explora as facilidades do hipertexto, possibilitando ao usuário/pesquisador um percurso não linear, através dos links recuperados nos resultados de pesquisa.

Ainda de acordo com Cunha (2008, p. 7),

O armazenamento digital amplia as possibilidades de pontos de acesso a um determinado documento. Nos sistemas manuais tradicionais e mesmo nos catálogos automatizados produzidos até o final dos anos 1980, as descrições mínimas restringiam-se a dados como autor, título e alguns cabeçalhos de 
assunto. Atualmente, dezenas de termos de indexação podem ser incluídos e, também, diversos níveis de representação do documento. Tais características agregam, sobremaneira, um alto grau de flexibilidade e qualidade na busca e recuperação da informação.

Todos esses serviços são oferecidos tanto aos usuários que estão presentes fisicamente na biblioteca, os quais efetuam suas buscas através do catálogo automatizado local ou aqueles que estão à distância, pela Internet, em catálogos on-line.

\subsection{SERVIÇOS ON-LINE}

Os catálogos automatizados vão além da simples busca e recuperação da informação. Observa-se uma gama de serviços remotos para os usuários, ocasionando facilidade e trazendo agilidade na localização da informação e permitindo um contato mais próximo entre usuário e biblioteca.

A seguir, serão abordados os principais serviços on-line, disponíveis nos catálogos das unidades de informação para os usuários das suas respectivas instituições:

a) Busca da informação

As consultas em linha introduzem uma flexibilidade nas buscas que seria impraticável nos sistemas impressos. Por conseguinte, torna-se mais necessário que o usuário se familiarize com uma ampla gama de recursos de busca e seu potencial, a fim de otimizar a utilização do sistema (ROWLEY, 2002, p. 163).

Inicialmente, os catálogos automatizados surgiram somente pela necessidade de substituírem os catálogos manuais e facilitar a busca pelos itens informacionais desejados. Vê-se que até os dias atuais, esta é a principal função deles, a de recuperar as obras de uma forma rápida, objetiva e confiável, poupando o tempo do usuário.

Antes, os campos de pesquisa eram, basicamente, autor, título e assunto, porém, os catálogos ampliaram o leque de opções e pode-se recuperar a informação também por resumos, palavras-chave, tipo de material, local, editora, série, número de chamada, ISBN etc.

Deve-se frisar também que, a maioria dos catálogos disponibiliza três ou mais interfaces de busca, as principais são a busca rápida onde normalmente a pesquisa é livre, podendo-se digitar qualquer termo dos principais campos indexados dos itens, inclusive mesclando vocábulos diferentes na mesma pesquisa como autor e título. Na busca simples, pode-se digitar palavras nos campos mais tradicionais como autor, título ou assunto. E a busca avançada permite uma maior interatividade entre usuário e catálogo, através de buscas mais pormenorizadas, mesclando vários campos e possibilitando a utilização de operadores booleanos.

Na maioria dos catálogos, as telas de respostas mostram o status do item informando se ele está disponível, emprestado, extraviado, em restauração, reservado, entre outros.

Outra importante função dos catálogos on-line é que alguns deles permitem ao usuário salvar, em sua conta pessoal ou no computador, as buscas realizadas com os dados dos itens em formato de referências, gerando um levantamento bibliográfico pessoal.

b) Renovação de obras 
Um serviço disponibilizado também para os usuários dos catálogos modernos é a renovação de itens, que permite adiar por mais um período de tempo às obras que estão em poder dos mesmos, sem a necessidade da presença física deles no ambiente da biblioteca.

Este serviço é importante tanto para o aluno, pois ele tem a comodidade de efetuá-lo em qualquer local, tendo apenas que ter um computador conectado a Internet, quanto para a biblioteca, que diminui o fluxo de usuários no balcão de atendimento.

c) Reserva de obras

Muitas vezes, o usuário vai à busca de um material que é pertinente para sua pesquisa, porém, não há qualquer exemplar disponível para empréstimo, estão todos na posse de outros usuários. Algumas bibliotecas oferecem o serviço de reserva, onde o usuário pode solicitar a reserva de um determinado título e ficar numa espécie de lista de espera aguardando o item solicitado.

Esse serviço pode ser realizado tanto nos catálogos na própria biblioteca, quanto em catálogos on-line. O usuário pode também consultar como está sua situação na lista de espera e o prazo aproximado da obra chegar para ele efetuar o empréstimo.

Alguns sistemas avisam ao usuário quando a obra é devolvida, através do próprio catálogo, e-mail e até mensagens de texto por celular via Short Message Service (SMS).

d) Histórico do usuário

Os catálogos permitem também aos usuários consultar a situação deles na biblioteca, os materiais que estão emprestados, a data de devolução prevista para os mesmos, histórico completo de todas as obras que eles pegaram na sua vida acadêmica, se ele está suspenso ou não, a data para que a suspensão expire, se o livro reservado já está disponível etc.

e) Mensagens pessoais para o usuário

Um relevante recurso utilizado pelo bibliotecário para comunicar-se com o usuário são as mensagens pessoais. O usuário ao acessar a sua conta através do catálogo, pode receber uma mensagem, cadastrada pelo bibliotecário ou funcionário da biblioteca, solicitando a sua presença física no setor ou o informando de algo importante para ele ou para a unidade de informação.

f) Disseminação Seletiva da Informação (DSI)

Muitos catálogos on-line permitem aos usuários, o cadastro de assuntos do seu interesse através da Disseminação Seletiva da Informação (DSI). No momento em que a biblioteca alimentar a base com itens destes assuntos, é enviado um e-mail informando ao usuário da chegada do material.

Podem-se observar uma infinidade de recursos disponibilizados pelas bibliotecas através de seus catálogos remotos. Cabe aos usuários saber usufruir destes recursos, facilitando suas pesquisas, fornecendo comodidade e segurança aos serviços à distância nas unidades de informação.

Porém, os catálogos on-line vão além dos serviços remotos. Outras funcionalidades são essenciais para garantir a disseminação da informação, como a disponibilização de acervos virtuais. 


\subsection{ACERVOS VIRTUAIS}

Uma grande parte das bibliotecas, na sua maioria universitárias, disponibiliza na íntegra, em seus catálogos, diversos documentos que podem ser acessados pela rede, muitas vezes até mesmo pelo público externo. Algumas solicitam apenas que efetue um breve cadastro para ter acesso aos itens.

Para Tammaro e Salarelli (2008), na atual fase de transição da biblioteca tradicional para a biblioteca digital, o fornecimento de documentos torna-se o elo entre o passado e futuro. Numa visão estratégica, a organização do serviço de fornecimento de documentos tem o objetivo de acelerar o processo evolutivo das bibliotecas.

Seguem abaixo alguns exemplos dos principais acervos virtuais disponibilizados em diversos catálogos de bibliotecas:

a) O Sistema de Bibliotecas da Universidade de Campinas (UNICAMP) oferece através de seu catálogo, no link: "busca combinada" dentre outros acervos, o de Teses. Quando se clica no ícone da obra desejada, o sistema dá a possibilidade de fazer o download completo da obra em Portable Document Format (PDF). Porém, no caso deste catálogo, deve-se realizar um breve cadastro para ter acesso a este tipo de documento.

b) A Biblioteca Central Zila Mamede (BCZM) da Universidade Federal do Rio Grande do Norte (UFRN), possui um acervo de literatura de cordel, onde, através de seu catálogo, disponibiliza as capas dos livros existentes no acervo físico da mesma e também cordéis com texto completo de autores que autorizaram sua publicação.

c) Algumas bibliotecas jurídicas dão acesso a diversas leis, atos, decretos, portarias, artigos e folhetos jurídicos na íntegra, podendo o usuário baixá-los e salvá-los ou apenas consultá-los na tela do seu computador, como é o caso da Biblioteca do Conselho da Justiça Federal.

d) Existem bibliotecas especializadas em música que dispõem em seus catálogos partituras musicais onde os usuários podem acessá-las, imprimi-las ou salvá-las auxiliando os estudantes e profissionais na prática e teoria musicais. A biblioteca da Faculdade de Música da Harvard University disponibiliza este tipo de material. Além de permitir ao usuário ouvir músicas e assistir vídeos.

e) A Biblioteca da Câmara de Deputados oferece a seus usuários a possibilidade de ouvir as sessões da Câmara dos Deputados, Congresso Nacional, Comissões e outros eventos.

f) A Biblioteca Nacional disponibiliza diversos catálogos remotos com variados acervos digitais, dentre eles manuscritos, material iconográfico, partituras, periódicos, mapas etc. Podese destacar o acervo cartográfico com algumas imagens e mapas históricos permitindo ao usuário ilustrar suas pesquisas e trabalhos.

g) Existem catálogos que disponibilizam artigos científicos, de periódicos ou não, em texto completo, desde que, evidentemente, devidamente autorizado pelos seus autores. Algumas instituições possibilitam imprimir e salvar, porém outras, apenas ler na própria tela do computador. Um exemplo é o catálogo da biblioteca da Universidade Federal do Ceará (UFC), que disponibiliza artigos de periódicos pela rede. 
As facilidades tornaram-se presentes com o surgimento das tecnologias da informação e as instituições que não as utilizam estão destinadas ao retrocesso. Não há mais espaço para bibliotecas convencionais.

\section{CONCLUSÃO}

Em uma biblioteca, o principal produto disponibilizado é a informação e o setor de processamento técnico é o responsável por tratar e fornecer essa informação aos usuários. Por isso, esse setor tem, provavelmente, a mais importante função dentro do ciclo documental.

A catalogação é extremamente relevante, mas observou-se que sem a utilização de normas, padrões e formatos internacionais ou ainda, sem fazer uso de terminologia adequada para a representação dos itens, ela pode prejudicar todo o processo de disseminação da informação.

Como foi abordado, há algumas décadas, as bibliotecas realizavam todas as suas atividades através de processos manuais, dificultando suas tarefas e criando alguns obstáculos para os usuários, tanto no atendimento aos serviços, quanto na busca pela informação desejada. Porém, hoje, a tecnologia da informação penetrou em todas as áreas do conhecimento humano e na Biblioteconomia, foram criados softwares específicos para as bibliotecas, que atuam em todas as suas atividades gerenciais e nos serviços disponibilizados.

No entanto, os sistemas de automação precisam adotar normas, padrões e formatos aceitos internacionalmente para que possam compartilhar dados, participando assim da cooperação bibliográfica, poupando o tempo dos bibliotecários.

Além disso, os sistemas automatizados auxiliam os usuários na busca e recuperação da informação, através de seus catálogos, que disponibilizam uma infinidade de recursos. É possível para o usuário realizar algumas operações como renovação e reserva de obras, visualização de histórico pessoal, além de manter contato com o bibliotecário e agendar diversos serviços.

Os catálogos automatizados das instituições vão ainda mais além, eles dão acesso a outros tipos de acervos através da rede. Muitos permitem o download de diversos materiais, a visualização de imagens, a audição de sons entre outros acervos virtuais.

Nesse sentido, torna-se indispensável para um bom sistema de automação em qualquer tipo de biblioteca, seja ela universitária, especializada, escolar ou comunitária, além de estar dentro das normas internacionais, procurar estar de acordo com o perfil de seus usuários.

Todas essas mudanças alteraram o modo como as pessoas tem visto a biblioteca hoje em dia. Se antes era vista como antiquada e de difícil acesso à informação, agora, torna-se mais acessível, ágil e segura, atraindo o usuário, graças, principalmente a automação e as diversas possibilidades de acesso à informação através dos catálogos on-line.

\section{REFERÊNCIAS}

1. BALBY, Cláudia Negrão. Curso formato USMARC. São Paulo: Ex Libris, [200-].

2. CAFÉ, Ligia; SANTOS, Christophe dos; MACEDO, Flávia. Proposta de um método para escolha de um software de automação de bibliotecas. Ciência da Informação, Brasília, v. 30, n. 2, p. 
70-79, maio/ago. 2001. Disponível em: <www.scielo.br/pdf/ci/v30n2/6213.pdf>. Acesso em: 13 jan. 2013.

3. CORRÊA, Rosa Maria Rodrigues. Catalogação descritiva no século XXI: um estudo sobre o RDA. 2008. 73 f. Dissertação (Mestrado em Ciência da Informação)- Faculdade de Filosofia e Ciências, Universidade Estadual Paulista, Marília, SP, 2008.

4. CÔRTE, Adelaide Ramos e et al. Automação de bibliotecas e centros de documentação: o processo de avaliação e seleção de softwares. Ciência da Informação, Brasília, v. 28, n. 3, p. 241-256, set./dez. 1999. Disponível em: <http://www.scielo.br/scielo.php?script=sci_arttext \&pid=s0100-19651999000300002>. Acesso em: 17 jan. 2013.

5. CÔRTE, Adelaide Ramos e et al. Avaliação de softwares para bibliotecas e arquivos: uma visão do cenário nacional. 2. ed. São Paulo: Polis, 2002.

6. CUNHA, Murilo Bastos da. Das bibliotecas convencionais às digitais: diferenças e convergências. Perspectivas em Ciência da Informação, Belo Horizonte, v. 13, n. 1, p. 2-17, jan./abr. 2008. Disponível em: <http://www.scielo.br/pdf/pci/v13n1/v13n1a02.pdf>. Acesso em: 25 out. 2012.

7. DZIEKANIAK, Gisele Vasconcelos et al. Uso do padrão MARC em bibliotecas universitárias da Região Sul do Brasil. Encontros Bibli: Revista Eletrônica de Biblioteconomia e Ciência da Informação, Florianópolis, n. 26, 2o sem. 2008. Disponível em: <http://www.periodicos. ufsc.br/index.php/eb/article/viewFile/7198/ 6645>. Acesso em: 11 fev. 2013.

8. GARCEZ, Eliane Maria Stuart; RADOS, Gregório J. Varvakis. Biblioteca híbrida: um novo enfoque no suporte à educação a distância. Ciência da Informação, Brasília, v. 31, n. 2, p. 4451, maio/ago. 2002. Disponível em: <http://www.scielo.br/pdf/ci/v31n2/12907.pdf>. Acesso em: 26 out. 2012.

9. GUSMÃO, Alexandre Oliveira de Meira. Avaliação da qualidade e determinantes de desempenho do Aleph 500 em bibliotecas universitárias brasileiras. 2001. $212 \mathrm{f}$. Dissertação (Mestrado em Ciência da computação)- Universidade Federal da Paraíba, João Pessoa, 2001.

10. KAFURE, Ivette. Usabilidade da imagem na recuperação da informação no catálogo público de acesso em linha. 2004. 311 f. Tese (Doutorado em Ciência da Informação)- Departamento de Ciência da Informação e Documentação, Faculdade de Estudos Sociais Aplicados, Universidade de Brasília, Brasília, 2004. Disponível em: <http://bdtd.bce.unb.br/tedesimpli ficado/tde_busca/processaArquivo.php? codArquivo=1011>. Acesso em: 5 out. 2012.

11. KRZYZANOWSKI, Rosaly Fávero et al. Implementação do Banco de Dados DEDALUS, do Sistema Integrado de Bibliotecas da Universidade de São Paulo. Ciência da Informação, Brasília, v. 26, n. 2, p. 168-176, maio/ago. 1997. Disponível em: <http://www.scielo.br/scielo. php?pid=S0100-19651997000200010\&script=sci_arttext>. Acesso em: 17 fev. 2013.

12. LOPES, Marcos Luiz Pereira. Catalogação cooperativa em redes de informação: estudo de caso da rede Bibliodata. 2010. $64 \mathrm{f}$. Monografia (Bacharelado em Biblioteconomia)Universidade de Brasília, Brasília, 2010. Disponível em: <http://bdm.bce.unb.br/bitstream /10483/959/1/2010_MarcosLuizLopes.pdf>. Acesso em: 22 ago. 2012.

13. LOURENÇO, Cíntia de Azevedo. Softwares nacionais $\mathbf{x}$ softwares estrangeiros em bibliotecas de universidades paulistas. 1998. 86 f. Dissertação (Mestrado em Biblioteconomia e Ciência da Informação)- Pontifícia Universidade Católica de Campinas, Campinas, 1998. Disponível 
em: <http://cintialourenco.eci.ufmg.br/downloads/LOURENCO_MESTRADO.pdf >. Acesso em: 15 abr. 2013.

14. MACIEL, Alba Costa; MENDONÇA, Marília Alvarenga Rocha. Bibliotecas como organizações. Rio de Janeiro: Interciência, 2000.

15. MEY, Eliane Serrão Alves; SILVEIRA, Naira Christofoletti. Catalogação no plural. Brasília: Briquet de Lemos, 2009.

16. MORENO, Fernanda Passini. Requisitos Funcionais para Registros Bibliográficos - FRBR: um estudo no catálogo da Rede Bibliodata. 2006. 199 f. Dissertação (Mestrado em Ciência da Informação)- Universidade de Brasília, Brasília, 2006. Disponível em: <http://repositorio .bce.unb.br/bitstream/10482/2565/1/DISSERTACAO\%20FERNANDA\%20MORENO\%20\%20UnB.pdf>. Acesso em: 25 ago. 2012.

17. NASCIMENTO, Maria Alice Rebello. Rede de catalogação cooperativa nacional ou catálogo coletivo. In: SEMINÁRIO NACIONAL DE BIBLIOTECAS UNIVERSITÁRIAS, 11., 2000, Florianópolis. Anais... Florianópolis: UFSC, 2000. Disponível em: <http://www8.fgv.br/ bibliodata/site2/informacoes/default.asp?id=1>. Acesso em: 20 set. 2012.

18. OLIVEIRA, Carla Cristina Vieira de. A interação de usuários com o catálogo on-line do Pergamum. Revista Brasileira de Biblioteconomia e Documentação, Nova Série, São Paulo, v. 4, n. 2, p. 73-88, jul./dez. 2008. Disponível em: <http://rbbd.febab.org.br /rbbd/article/view/104>. Acesso em: 19 ago. 2012.

19. OLIVEIRA, Zita Prates de et al. O uso do campo MARC 9XX para controle bibliográfico institucional. Ciência da Informação, Brasília, v. 33, n. 2, p. 179-186, maio/ago. 2004. Disponível em: <http://www.scielo.br/pdf/ci/v33n2/a19v33n2.pdf>. Acesso em: 11 abr. 2013.

20. PONTIFÍCIA UNIVERSIDADE CATÓLICA DO RIO DE JANEIRO. Divisão de Bibliotecas e Documentação. Marc 21: formato bibliográfico. Rio de Janeiro, 2010. Disponível em: <http://www.dbd.puc-rio.br/MARC21/conteudo.html>. Acesso em: 24 ago. 2012.

21. ROSETTO, Márcia. Uso do protocolo Z39.50 para recuperação de informação em redes eletrônicas. Ciência da Informação, v. 26, n. 2, 1997. Disponível em: <http://revista.ibict .br/ciinf/index.php/ciinf/article/download/391/351>. Acesso em: 08 ago. 2012.

22. ROWLEY, Jennifer. A biblioteca eletrônica. Tradução de Antonio Agenor Briquet de Lemos. Brasília: Briquet de Lemos, 2002.

23. SANTOS, Denise Lourenço dos; SANTOS, Plácida L. V. C. A. Catalogação cooperativa: atualidade. 2007. Disponível em: <http://www.slideshare.net/Re_Biblio/catalogaocentralizada>. Acesso em: 19 ago. 2012.

24. SANTOS, Plácida L. V. C. A.; GALO, Fernanda Cristina Menezes. Conversão retrospectiva. Disponível em: <http://www.slideshare.net/Re_Biblio/catalogao-retrospectiva>. Acesso em: 19 ago. 2012.

25. TAMMARO, Anna Maria; SALARELLI, Alberto. A biblioteca digital. Tradução de Antonio Agenor Briquet de Lemos. Brasília: Briquet de Lemos, 2008. 